\title{
TITLE:
}

\section{First-principles study of vacancy formation in hydroxyapatite}

$\operatorname{AUTHOR}(S)$ :

Matsunaga, K; Kuwabara, A

\section{CITATION:}

Matsunaga, K ... [et al]. First-principles study of vacancy formation in hydroxyapatite. PHYSICAL REVIEW B 2007, 75(1): 014102.

\section{ISSUE DATE:}

2007-01

URL:

http://hdl.handle.net/2433/50125

RIGHT:

Copyright 2007 American Physical Society 
PHYSICAL REVIEW B 75, 014102 (2007)

\title{
First-principles study of vacancy formation in hydroxyapatite
}

\author{
Katsuyuki Matsunaga and Akihide Kuwabara \\ Department of Materials Science and Engineering, Kyoto University, Yoshida-Honmachi, Sakyo, Kyoto 606-8501, Japan
}

(Received 11 July 2006; revised manuscript received 30 October 2006; published 5 January 2007)

\begin{abstract}
First-principles plane-wave calculations were performed for hydroxyapatite (HAp) in order to investigate the electronic structure and vacancy formation mechanisms. The HAp unit cell contains $\mathrm{PO}_{4}$ tetrahedra and $\mathrm{OH}$ groups formed by covalent $\mathrm{P}-\mathrm{O}$ and $\mathrm{H}-\mathrm{O}$ bonds. Ca ions play a role for connecting the $\mathrm{PO}_{4}$ tetrahedra and $\mathrm{OH}$ groups in an ionic character of bonding. It is found that $\mathrm{OH}^{-}$vacancies with accompanying $\mathrm{H}^{+}$vacancies are dominantly formed and that their spontaneous formation takes place at temperatures above $1000 \mathrm{~K}$. This corresponds to the nonstoichiometry of HAp due to $\mathrm{OH}$ deficiency that is experimentally observed near $1073 \mathrm{~K}$.
\end{abstract}

DOI: 10.1103/PhysRevB.75.014102

PACS number(s): 61.72.Ji, 71.15.Mb

\section{INTRODUCTION}

Calcium apatites have recently received special attention in materials science due to their importance in medicine and dentistry. In this group of materials, hydroxyapatite [HAp, $\left.\mathrm{Ca}_{5}\left(\mathrm{PO}_{4}\right)_{3} \mathrm{OH}\right]$ is a main component in natural human bones and teeth and is thus considered as a promising material used for bone and tooth replacement. ${ }^{1,2}$ In order to attain biological compatibility and an affinity of artificially fabricated HAp for human tissue, it is necessary to control the chemical composition and the relevant physical and chemical properties of HAp; thus, a fundamental understanding of the atomic and electronic structures of HAp is indispensable.

Regarding the crystal structure of HAp, there have been a number of experimental studies mainly using $\mathrm{x}$-ray and neutron diffraction. ${ }^{1,3-5}$ Two kinds of somewhat complicated crystal structures, monoclinic (space group $P 2_{1} / b$ ) and hexagonal $\left(P 6_{3} / \mathrm{m}\right)$, were experimentally reported, both of which are basically composed of $\mathrm{PO}_{4}$ tetrahedra, $\mathrm{OH}$ groups arranged along the $c$ axis, and $\mathrm{Ca}$ ions in between. Since preparing stoichiometric HAp is experimentally difficult and HAp has ion-exchange ability, ${ }^{1}$ it is thought that the stability of the HAp structures strongly depends on the presence of point defects such as vacancies and substitutional ions. It was also reported that a considerable number of vacancies related to the $\mathrm{OH}$ groups can be easily formed in HAp at high temperature ${ }^{6,7}$ and may also lead to the observed proton conductivity of HAp. ${ }^{8}$

First-principles calculations have been proven to predict stable point defects formed in many metal oxides ${ }^{9-11}$ and can therefore be applied to HAp for studying a point-defect formation mechanism. Previously, a number of groups performed first-principles calculations for HAp. ${ }^{12-15}$ For example, Calderín et al. employed a pseudopotential method to investigate the electronic structures of a series of stoichiometric apatites $\left[\mathrm{Ca}_{5}\left(\mathrm{PO}_{4}\right)_{3} X, X=\mathrm{F}, \mathrm{Cl}, \mathrm{OH}, \mathrm{O}_{0.5}\right]$ and discussed the relative stability between monoclinic and hexagonal structures in the cases of $X=\mathrm{OH}$ and $\mathrm{Cl}$ based on their total energies. ${ }^{12}$ Rulis et al. used the orthogonalized linear combination of the atomic orbital method for the apatites and showed their chemical bonding states and theoretical optical spectra. ${ }^{13}$ These studies provide detailed information on the electronic structures of the calcium apatites and yet mainly focused on the perfect-lattice properties. More recently, the stable point-defect structure in Si-doped HAp has also been reported. ${ }^{14}$ An understanding of the defect chemistry in HAp will be important for biomaterials applications.

In this paper, first-principles plane-wave calculations are performed to reveal electronic structures and stable point defects in HAp. Especially, vacancies introduced in HAp by annealing at high temperatures are investigated. The obtained results are compared with available experiments, and the characteristic behavior of the vacancy formation in HAp is discussed.

\section{COMPUTATIONAL PROCEDURE}

To begin with, crystal structures and atomic coordinates in HAp are briefly reviewed. ${ }^{1}$ Figure 1(a) shows a schematic illustration of the hexagonal primitive cell of HAp (total 44 atoms) which contains two inequivalent $\mathrm{Ca}$ sites $[\mathrm{Ca}(\mathrm{I})$ and $\mathrm{Ca}(\mathrm{II})]$, one $\mathrm{P}$ site, four different oxygen sites [O(I), O(II), $\mathrm{O}(\mathrm{III})$, and $\mathrm{O}(\mathrm{IV})]$, and one $\mathrm{H}$ site located along the $c$ axis. The $\mathrm{P}$ atom forms a $\mathrm{PO}_{4}$ tetrahedron with $\mathrm{O}(\mathrm{I}), \mathrm{O}(\mathrm{II})$, and two $\mathrm{O}$ (III) atoms, and the tetrahedra are linked via $\mathrm{Ca}(\mathrm{I})$ and/or $\mathrm{Ca}(\mathrm{II})$ along the $c$ axis. In this case, $\mathrm{Ca}$ (I) is coordinated to three $\mathrm{O}(\mathrm{I})$ and three $\mathrm{O}(\mathrm{II})$ atoms with bond lengths of around $0.24 \mathrm{~nm}$, while $\mathrm{Ca}(\mathrm{II})$ has a sixfold coordination with an $\mathrm{O}(\mathrm{II})$ atom, four $\mathrm{O}(\mathrm{III})$ atoms, and an $\mathrm{O}(\mathrm{IV})$ atom. $\mathrm{Ca}$ (II) atoms also form triangles at $\mathrm{z}=1 / 4$ and $3 / 4$ (normal to the $c$ axis), and $\mathrm{O}(\mathrm{IV})$ and $\mathrm{H}$ form $\mathrm{OH}$ groups that are oriented along the $c$ axis and penetrate the centers of the $\mathrm{Ca}$ (II) triangles. This hexagonal structure was originally found to have a space group of $P 6_{3} / \mathrm{m}$ with mirror planes perpendicular to the $c$ axis at $\mathrm{z}=1 / 4$ and $3 / 4$. In this case, the structure has four possible sites for $\mathrm{OH}$ groups along the $c$ axis, each of which is considered to have a site occupancy of 0.5. It is noted that the $\mathrm{OH}$ groups may undergo disorder in the column. ${ }^{16}$ In the present calculations, the mirror symmetry with respect to the $\mathrm{OH}$ columns is not considered, and it is assumed that two $\mathrm{OH}$ groups are present along the $c$ axis. The detailed $\mathrm{OH}$-group arrangement will be described below.

First-principles plane-wave-based calculations for HAp are performed using the VASP code. ${ }^{17,18}$ Electron-ion interactions are described using the projector augmented wave 
(a)

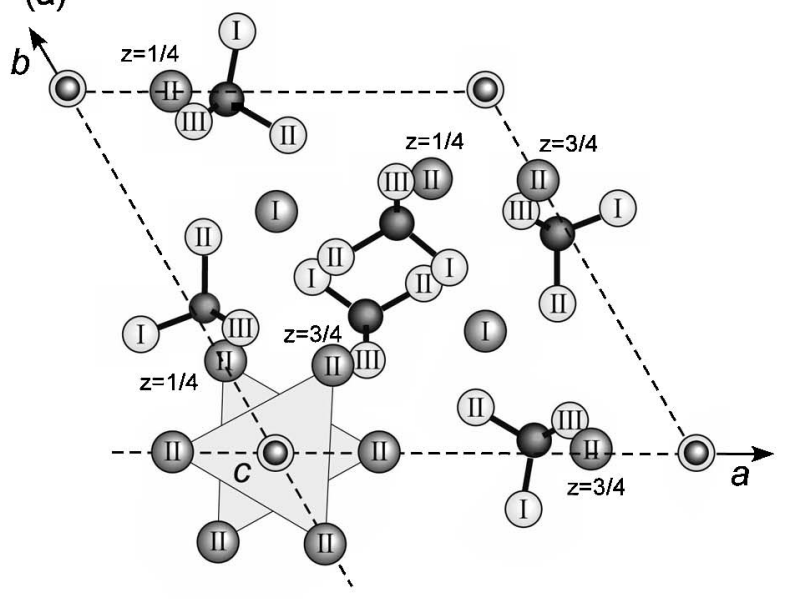

(b)

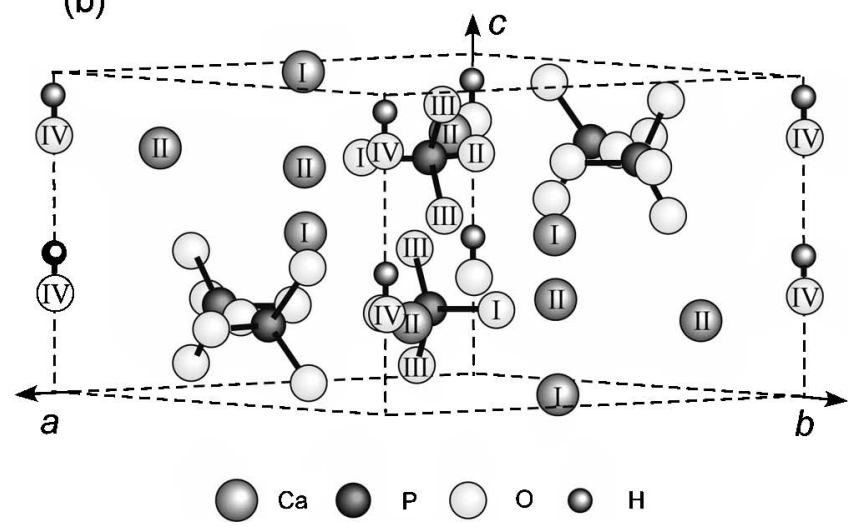

FIG. 1. An illustration of unit-cell structure of hexagonal HAp. $\mathrm{P}$ and $\mathrm{O}$ atoms forming the tetrahedra are connected by thick lines. The fractional $z$ coordinates inserted here are for $\mathrm{Ca}(\mathrm{II})$. Triangles of $\mathrm{Ca}(\mathrm{II})$ at $z=1 / 4$ and $3 / 4$ are depicted by the shaded triangles in (a).

(PAW) method, ${ }^{19,20}$ and $3 p 4 s 3 d$ for $\mathrm{Ca}, 3 s 3 p$ for $\mathrm{P}, 2 s 2 p$ for $\mathrm{O}$, and $1 s$ for $\mathrm{H}$ are treated as valence orbitals. Electronic wave functions are expanded with plane waves up to an energy cutoff $\left(E_{\text {cut }}\right)$ of $500 \mathrm{eV}$. The GGA functional of Perdew, Burke, and Ernzerhof (PBE) is used for the exchangecorrelation potential. ${ }^{21}$ For the primitive hexagonal HAp cell, Brillouin zone sampling is performed on a Monkhorst-Pack (MP) $\mathrm{mesh}^{22}$ of $2 \times 2 \times 3$ centered at the $\Gamma$ point (four irreducible $k$-points). As compared to calculations using a denser MP mesh of $4 \times 4 \times 6$, the total energy is confirmed to converge to less than $1.0 \mathrm{meV} /$ atom. For geometrical optimization, atoms are allowed to relax until their forces converge to less than $0.02 \mathrm{eV} / \AA$.

Regarding the $\mathrm{OH}$-group orientation along the $c$ axis, there are two possible arrangements of -OH-OH- and -OH-HO-. The two types of HAp unit cells with the different $\mathrm{OH}$ arrangements were calculated with structural optimization, and it is found that the $-\mathrm{OH}-\mathrm{OH}$ - orientation has a smaller total energy by about $0.2 \mathrm{eV}$ per formula unit, as compared to the -OH-HO- orientation. Therefore, hexagonal HAp with the - $\mathrm{OH}-\mathrm{OH}-$ orientation is used as a starting
TABLE I. Comparison of the calculated unit-cell parameters for HAp with previous $a b$ initio and experimental results.

\begin{tabular}{lllc}
\hline \hline \multicolumn{1}{c}{ This work } & \multicolumn{1}{c}{ Calc. $(\mathrm{LDA})^{\mathrm{a}}$} & \multicolumn{1}{c}{ Experiment } \\
\hline Lattice parameters & & \\
$a=b(\AA)$ & 9.536 & 9.11 & $9.4302,{ }^{\mathrm{b}} 9.4214^{\mathrm{c}}$ \\
$c(\AA)$ & 6.904 & 6.86 & $6.8911,{ }^{\mathrm{b}} 6.8814^{\mathrm{c}}$ \\
Fractional coordinate & & \\
$\mathrm{O}(\mathrm{IV})$ & $(0.0,0.0,0.286)$ & $(0.0,0.0,0.29)$ & $(0.0,0.0,0.298)^{\mathrm{b}}$ \\
$\mathrm{H}$ & $(0.0,0.0,0.428)$ & $(0.0,0.0,0.42)$ & $(0.0,0.0,0.442)^{\mathrm{b}}$ \\
\hline
\end{tabular}

${ }^{\mathrm{a}}$ Reference 12.

${ }^{\mathrm{b}}$ Reference 4 .

${ }^{\mathrm{c}}$ Reference 5 .

structure [see Fig. 1(b)] to investigate the electronic structures and defect-formation energies in HAp.

It is noted here that HAp has a low-temperature monoclinic phase with a space group of $\mathrm{P} 2{ }_{1} / b .{ }^{1}$ The monoclinic structure can be obtained by doubling the hexagonal unit cell along the $b$ axis. The OH-group orientations in the neighboring $\mathrm{OH}$ columns are not the same with each other, and the -OH-OH- columns with + and $-c$-axis orientations are alternately arranged in the $b$ direction. In order to check the relative stability against the hexagonal phase, the monoclinic unit cell (88 atoms) was also calculated using $E_{\text {cut }}$ of $500 \mathrm{eV}$ and a $2 \times 1 \times 3 \mathrm{MP}$ mesh. It is found that the total energy of the monoclinic phase is smaller by about $0.03 \mathrm{eV}$ per formula unit than that of the hexagonal one. Such a small difference in total energies between the two phases is also reported by Calderín et al. ${ }^{12}$ Owing to the similar stability, it is reasonable to calculate the hexagonal phase in order to analyze the fundamental electronic structure of HAp in a firstprinciples manner.

Unit-cell parameters of hexagonal HAp calculated here are listed in Table I, together with available theoretical and experimental data. It is found that the lattice parameters $a$ and $c$ in the present study are larger than the previous firstprinciples result using a pseudopotential technique within the local density approximation (LDA), ${ }^{12}$ and that our results are in better agreement with experiment (less than $1.2 \%$ error). For calcium apatites $\mathrm{Ca}_{5}\left(\mathrm{PO}_{4}\right)_{3} X$, the anion $X$ position along the $c$ axis is often used to discuss their structural difference. Accordingly, the $\mathrm{O}(\mathrm{IV})$ and $\mathrm{H}$ coordinates are shown in the table. The $\mathrm{OH}$ group is located slightly above $z=1 / 4$, and such a structural characteristic in HAp is also observed in the previous theoretical and experimental results. ${ }^{4,12}$ As a result, the $\mathrm{O}$ (IV) atom is coordinated to three $\mathrm{Ca}(\mathrm{II})$ atoms with a bond length of $0.24 \mathrm{~nm}$ and is also bonded to a $\mathrm{H}$ atom (about $0.10 \mathrm{~nm}$ in length) on the opposite side of the $\mathrm{Ca}$ (II) triangle.

According to the optimized unit-cell parameters, HAp supercells are constructed to evaluate formation energies of isolated vacancies in hexagonal HAp. The supercells containing 88 atoms are obtained by doubling the hexagonal primitive HAp cell along the $c$ axis, and a particular atom or ion group is removed to form a vacancy. $k$-point sampling 
using a $2 \times 2 \times 1$ MP mesh is performed for the vacancy supercells. All atoms are allowed to relax until the residual forces are less than $0.05 \mathrm{eV} / \AA$, in order to obtain total energies of the defective supercells. It is noted that test calculations using the monoclinic 176-atom supercell (doubling the unit cell along the $c$ axis) were also performed for the $\mathrm{H}^{+}$and $\mathrm{OH}^{-}$vacancy pair and showed the formation-energy difference of about $0.02 \mathrm{eV} / \mathrm{defect}$, as compared to the hexagonal 88 -atom supercell calculation. Such a small energy difference ensures that using the hexagonal supercell is a good approximation to study vacancy formation energies in HAp.

From total energies $\left(E_{\mathrm{t}}\right)$ of the perfect and defective supercells, a formation energy $\left(\Delta H_{\mathrm{f}}\right)$ of an isolated vacancy in a charge state of $q$ is calculated as follows:

$$
\Delta H_{\mathrm{f}}=E_{\mathrm{t}}(\text { defect } ; q)-E_{\mathrm{t}}(\text { perfect })+\mu_{\mathrm{M}}+q\left(E_{\mathrm{VBM}}+\varepsilon_{\mathrm{F}}\right),
$$

where $\mu_{\mathrm{M}}$ is the atomic chemical potential for an atomic species $\mathrm{M}$ that is removed to form the vacancy, and $\varepsilon_{\mathrm{F}}$ is the Fermi level measured from the valence band maximum $\left(E_{\mathrm{VBM}}\right)$. The $E_{\mathrm{VBM}}$ is determined from the supercell calculations, but the $E_{\mathrm{VBM}}$ in the defective supercells is affected by effects of the finite supercell size and the background charge neutralizing the supercell charges. In order to line up the band structures of the perfect and charged defective supercells, the energy correction based on the average potentials $\left(V_{\mathrm{av}}\right)$ is performed in the following manner:

$$
E_{\mathrm{VBM}}=E_{\mathrm{VBM}}(\text { perfect })+V_{\mathrm{av}}(\text { defect })-V_{\mathrm{av}}(\text { perfect }) .
$$

The $V_{\text {av }}$ (defect) is obtained from that at particular atomic sites far from the vacancy site (bulklike environment). More details of this procedure was described elsewhere. ${ }^{10}$ Also, the Fermi energy $\varepsilon_{\mathrm{F}}$ has to be determined to obtain $\Delta H_{\mathrm{f}}$. Since charge-compensating vacancy reactions in HAp are considered in this study, however, it is not necessary to take account of $\varepsilon_{\mathrm{F}}$ explicitly.

In the present study, only $\mathrm{O}, \mathrm{H}, \mathrm{OH}$, and $\mathrm{Ca}$ vacancies in HAp are considered because these vacancies are expected to be relatively easy to form in HAp, according to the experimental results on the formation of HAp with $\mathrm{Ca}$ and $\mathrm{OH}$ deficiency. ${ }^{1,6,7}$ Vacancy charges $q$ from neutral to fully ionized states are considered, but a fully ionized state of $\mathrm{V}_{\mathrm{Ca}^{2+}}$ is only calculated for Ca vacancies. Values of $\mu_{\mathrm{O}}, \mu_{\mathrm{H}}$, and $\mu_{\mathrm{Ca}}$, which are required for the formation-energy calculations, are determined by assuming that HAp is equilibrated with solid $\mathrm{CaO}$ in air containing water vapor. This is because it is known that $\mathrm{CaO}$ is more stable than $\mathrm{Ca}(\mathrm{OH})_{2}$ at temperatures of more than about $850 \mathrm{~K}$. Then the atomic chemical potentials can be expressed in the following manner.

$$
\begin{gathered}
\mu_{\mathrm{O}}=\frac{1}{2} \mu_{\mathrm{O}_{2} \text { (gas) }}, \quad \mu_{\mathrm{H}}=\frac{1}{2} \mu_{\mathrm{H}_{2} \text { (gas) }}, \\
\mu_{\mathrm{CaO} \text { (solid) }}=\mu_{\mathrm{Ca}}+\mu_{\mathrm{O}}, \quad \mu_{\mathrm{H}_{2} \mathrm{O} \text { (gas) }}=2 \mu_{\mathrm{H}}+\mu_{\mathrm{O}} .
\end{gathered}
$$

It is reasonable to consider that the temperature and pressure dependence of the chemical potentials for the gas phases is not negligible. Then, the $\mu_{\mathrm{O}}$ and $\mu_{\mathrm{H}}$ with partial pressure $p$ at a temperature $T$ can be written as

$$
\begin{aligned}
& \mu_{\mathrm{O}}=\frac{1}{2} \mu_{\mathrm{O}_{2} \text { (gas) }}=\frac{1}{2} \mu_{\mathrm{O}_{2}}^{0}+\frac{k_{\mathrm{B}} T}{2} \ln p_{\mathrm{O}_{2}}, \\
& \mu_{\mathrm{H}}=\frac{1}{2} \mu_{\mathrm{H}_{2} \text { (gas) }}=\frac{1}{2} \mu_{\mathrm{H}_{2}}^{0}+\frac{k_{\mathrm{B}} T}{2} \ln p_{\mathrm{H}_{2}},
\end{aligned}
$$

where $k_{\mathrm{B}}$ is the Boltzmann constant, and $\mu^{0}$ means a chemical potential in the standard state at a pressure of $1 \mathrm{~atm}$ and a temperature of $T . \mu^{0}$ at $298 \mathrm{~K}$ is conventionally set to zero in thermodynamics, but this definition is not directly applicable to the present first-principles results. In the case of $\mathrm{O}_{2}$, for example, the $\mu_{\mathrm{O}_{2}}^{0}$ is expressed in terms of enthalpy $H(T)$ and entropy $S(T)$,

$$
\begin{aligned}
\mu_{\mathrm{O}_{2}}^{0}= & H_{\mathrm{O}_{2}}(T)-T S_{\mathrm{O}_{2}}(T)=H_{\mathrm{O}_{2}}(0)+\left[H_{\mathrm{O}_{2}}(T)-H_{\mathrm{O}_{2}}(0)\right] \\
& -T S_{\mathrm{O}_{2}}(T) .
\end{aligned}
$$

The temperature-dependent enthalpy and entropy, corresponding to the 2nd and 3rd terms in Eq. (5), can be found in tables of thermodynamic data. ${ }^{23}$ By using the total energy of the isolated molecule as the enthalpy at $T=0 \mathrm{~K}\left[H_{\mathrm{O}_{2}}(0)\right]$, the oxygen chemical potential at given $p$ and $T$ can be obtained. In a similar way, $\mu_{\mathrm{H}_{2}}^{0}$ is also evaluated from the total energy of an $\mathrm{H}_{2}$ molecule combined with thermodynamic data.

It is noted that the temperature effects of enthalpy and entropy for the solid phases are not considered, in evaluation of the atomic chemical potentials. The recent phonon calculation using the shell model ${ }^{24}$ indicates anharmonic thermal vibrations of $\mathrm{OH}$ groups and oxygen ions in $\mathrm{HAp}$, which may contribute to vibrational entropies of HAp. It is expected, however, that the phonon calculation of HAp from first principles is demanding, which is beyond the scope of this study. As a first approximation, therefore, the temperature-dependent chemical potentials are explicitly considered only for the gas phases.

Considering the relation $\mu_{\mathrm{H}_{2} \mathrm{O}}=2 \mu_{\mathrm{H}}+\mu_{\mathrm{O}}$, the following correlations among partial pressures of the gas phases are given:

$$
\begin{gathered}
\mu_{\mathrm{H}_{2} \mathrm{O}}^{0}-\mu_{\mathrm{H}_{2}}^{0}-\frac{1}{2} \mu_{\mathrm{O}_{2}}^{0}=-k_{\mathrm{B}} T \ln \frac{p_{\mathrm{H}_{2} \mathrm{O}}}{p_{\mathrm{H}_{2}} p_{\mathrm{O}_{2}}{ }^{1 / 2}}, \\
\frac{p_{\mathrm{H}_{2} \mathrm{O}}}{p_{\mathrm{H}_{2}} p_{\mathrm{O}_{2}}{ }^{1 / 2}}=\exp \left\{-\left(\mu_{\mathrm{H}_{2} \mathrm{O}}^{0}-\mu_{\mathrm{H}_{2}}^{0}-\frac{1}{2} \mu_{\mathrm{O}_{2}}^{0}\right) / k_{\mathrm{B}} T\right\}=K(T) .
\end{gathered}
$$

The equilibrium constant $K(T)$ for $\mathrm{H}_{2} \mathrm{O}$ (gas) $=\mathrm{H}_{2}$ (gas) $+\frac{1}{2} \mathrm{O}_{2}$ (gas) is also found in the thermodynamic tables. ${ }^{23}$ When two of the three gas-phase partial pressures are given, the pressure-dependent terms in Eq. (4) for oxygen and hydrogen can be determined. Since the present study considers the situation of HAp annealed in an air atmosphere with water vapor of a relatively small $p_{\mathrm{H}_{2} \mathrm{O}}, p_{\mathrm{O}_{2}}$ is set to $0.2 \mathrm{~atm}$ throughout the vacancy-formation analyses, and $p_{\mathrm{H}_{2} \mathrm{O}}$ is treated as a variable parameter. 


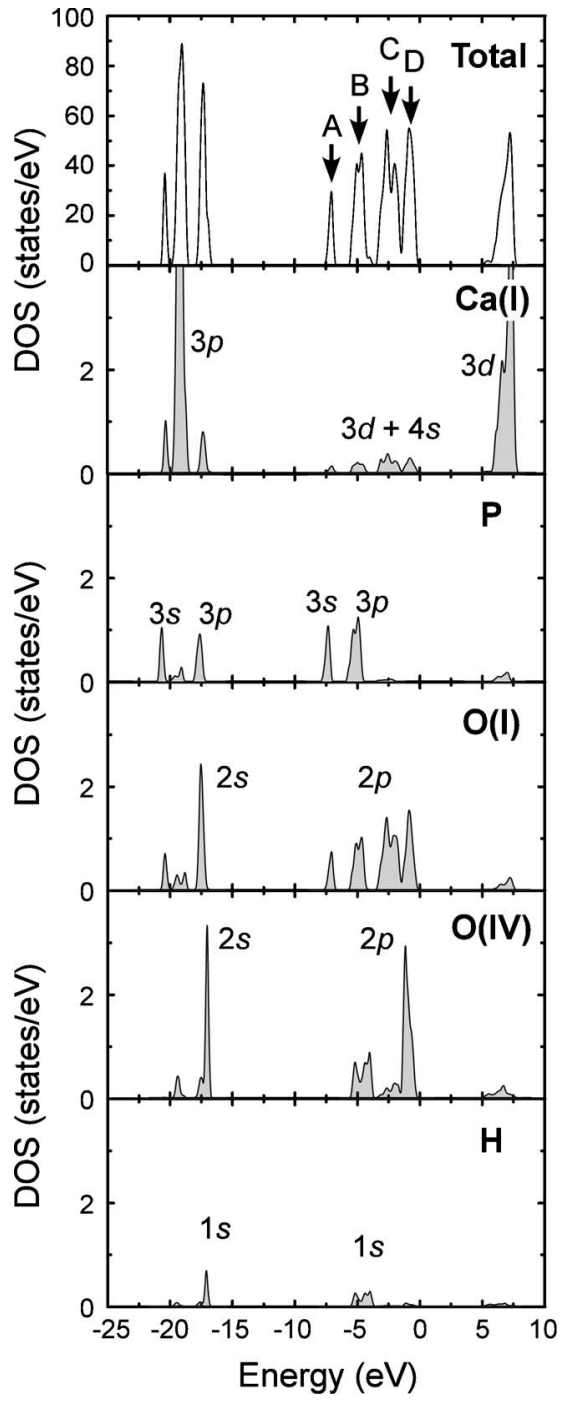

FIG. 2. Total and partial DOS curves for valence band of hexagonal HAp. Since the upper valence band can be divided by four peaks, they are denoted by A-D.

\section{RESULTS AND DISCUSSION}

\section{A. Bulk electronic structure}

Figure 2 shows the total density of states (DOS) and atom-projected partial DOS (PDOS) profiles for the valence band (VB) of hexagonal HAp. It is noted that the PDOS profiles of $\mathrm{Ca}(\mathrm{II}), \mathrm{O}(\mathrm{II})$, and $\mathrm{O}$ (III) are not shown here, because it is found that they are quite similar to that of $\mathrm{Ca}(\mathrm{I})$ and $\mathrm{O}(\mathrm{I})$, respectively. In the total DOS, the upper VB, which ranges from $-7.5 \mathrm{eV}$ to $0 \mathrm{eV}$, mainly arises from $\mathrm{O} 2 p$ components, while the lower VB at around $-20 \mathrm{eV}$ is composed of $\mathrm{O} 2 p$ and $\mathrm{Ca} 3 p$ components. $\mathrm{Ca} 3 d$ components dominate near the bottom of the conduction band, and the calculated band gap of $5.3 \mathrm{eV}$ agrees well with the LDA result $(5.4 \mathrm{eV}) .{ }^{12}$ To our knowledge, the experimental band-gap value of HAp was not reported. However, the theoretical band gap from the GGA and LDA calculations may underestimate it. (a)

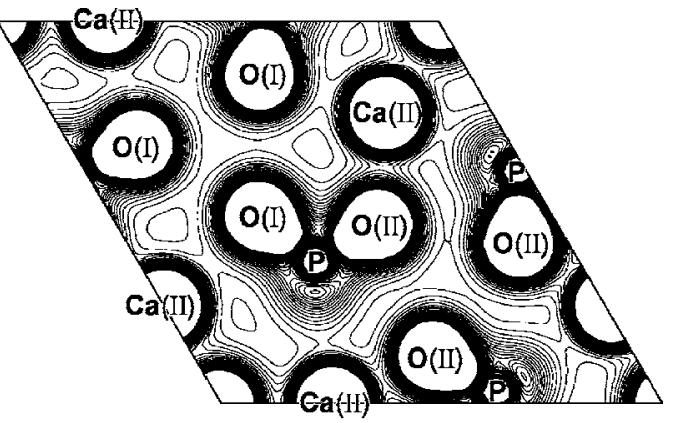

(b)

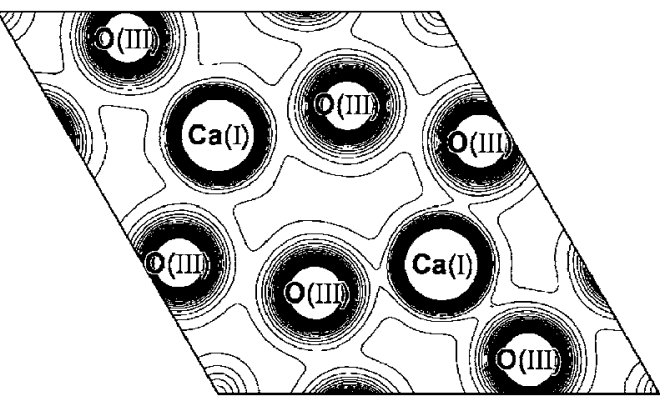

(c)

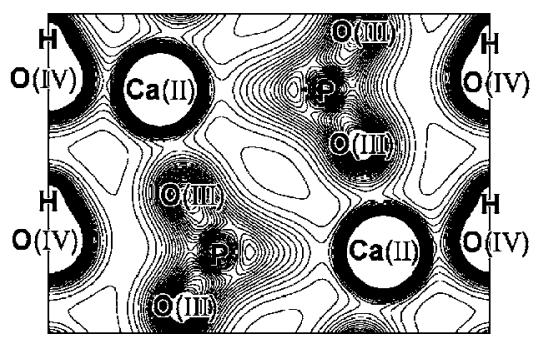

FIG. 3. Contour maps of electron densities calculated for hexagonal HAp. Electron densities on different $\{0001\}$ planes at (a) $z$ $=1 / 4$ and (b) $z=1 / 2$, while (c) on an $\{1 \overline{1} 00\}$ plane. The contour lines are drawn from 0.0 to 1.0 with an interval of 0.04 (in electrons/ $\AA$ ).

It is worth mentioning here that the upper VB arising from $\mathrm{O} 2 p$ components exhibits a characteristic feature described by four peaks of A-D. It can be seen from the PDOS curves that the peak $\mathrm{A}$ is composed mainly of $\mathrm{P} 3 s$ and $\mathrm{O}(\mathrm{I})-2 p$ components, while the $\mathrm{P} 3 p$ and $\mathrm{O}(\mathrm{I}) 2 p$ orbitals mainly contribute to the peak $\mathrm{B}$. The similar feature can also be observed in the lower VB, where O $2 s$ orbitals are admixed with $\mathrm{P} 3 s$ and $\mathrm{P} 3 p$ orbitals at the peaks around $-21 \mathrm{eV}$ and $-18 \mathrm{eV}$. These indicate that $\mathrm{P} 3 s p$ and $\mathrm{O} 2 s p$ orbitals considerably overlap with each other, which results in strong covalent bonds of P-O. The peaks $\mathrm{C}$ and $\mathrm{D}$ arise from $\mathrm{O} 2 p$ with small contributions from $\mathrm{Ca} 4 s$ and $3 d$. Hence, peaks $\mathrm{C}$ and $\mathrm{D}$ are mainly related to $\mathrm{Ca}-\mathrm{O}$ interactions connecting neighboring $\mathrm{PO}_{4}$ tetrahedra or $\mathrm{OH}$ groups in the HAp structure. In contrast, the PDOS of O(IV) shows a different profile from that of $\mathrm{O}(\mathrm{I})$. A prominent peak of $\mathrm{O}$ (IV) $2 p$ is located at around peak D of the total DOS, and the smaller and broader components of O(IV) $2 p$ at around $-5 \mathrm{eV}$ originate from admixture with $\mathrm{H} 1 s$ orbitals. Such differences in the PDOS curves for $\mathrm{O}(\mathrm{I})$ and $\mathrm{O}(\mathrm{IV})$ indicate 

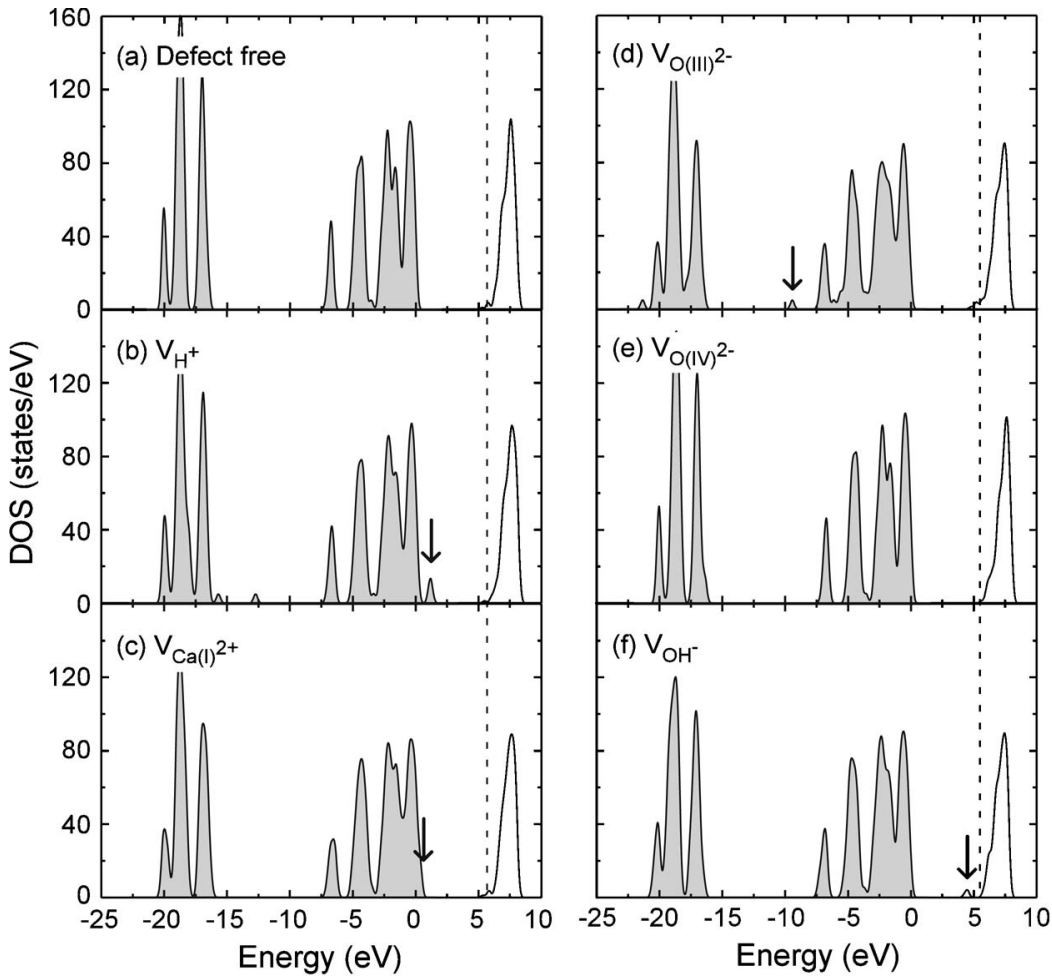

FIG. 4. Total DOS curves for the perfect and defective supercells. The VBM is set at $0 \mathrm{eV}$, and the vertical broken line indicates the CBM in the perfect lattice. The shaded areas denote electronoccupied bands. that the two oxygen atoms are in quite different chemical environments from each other.

Figure 3 displays electron-density (ED) maps on cross sections of the $\{0001\}$ and $\{1 \overline{1} 00\}$ planes. As is seen in Figs. 3(a) and 3(c), EDs of O(I), O(II), and O(III) are not spherical but exhibit oval shapes pointing to the neighboring $\mathrm{P}$ ions. This can be imagined from the strong orbital overlaps between $\mathrm{P}$ and $\mathrm{O}$ in the lower and upper VBs, as shown in Fig. 2. The $\mathrm{O}(\mathrm{IV})$ atom also shows considerable ED overlap with the neighboring $\mathrm{H}$ atom, forming $\mathrm{OH}$ groups arranged along the $c$ axis.

In contrast, it is observed that the ED of the $\mathrm{Ca}$ atoms show relatively small overlap with the adjacent $\mathrm{O}$ atoms. This corresponds to the small contributions of $\mathrm{Ca} 3 d$ and $4 s$ orbitals in the upper VB (see Fig. 2). Therefore, $\mathrm{Ca}$ atoms no longer form covalent bonds with $\mathrm{O}$ atoms, and yet have ionic interactions, so as to make linkages of $\mathrm{O}^{2-}-\mathrm{Ca}^{2+}-\mathrm{O}^{2-}$ in the space between $\mathrm{PO}_{4}$ tetrahedra and $\mathrm{OH}$ groups. From the above results, it can be said that the HAp structure is composed of $\mathrm{PO}_{4}$ tetrahedra and $\mathrm{OH}$ groups having strong internal bonds, and the $\mathrm{PO}_{4}$ and $\mathrm{OH}$ units are connected via $\mathrm{Ca}$ atoms in an ionic character of bonding.

\section{B. Electronic structures around vacancies}

In this section, electronic structures around vacancies in HAp are investigated. Figure 4 displays total DOS curves for the defect-free and defective supercells. For the vacancies, the DOS profiles for their fully charged states are considered, and the $E_{\mathrm{VBT}}$ values are corrected by the average potentials, which are set at $0 \mathrm{eV}$ in this figure. The results for $\mathrm{V}_{\mathrm{Ca}(\mathrm{II})^{2+} \text {, }}$ $\mathrm{V}_{\mathrm{O}(\mathrm{I})^{2-}}$, and $\mathrm{V}_{\mathrm{O}(\mathrm{II})^{2-}}$ are not displayed because they are similar to the DOS curves for $\mathrm{V}_{\mathrm{Ca}(\mathrm{I})^{2+}}$ and $\mathrm{V}_{\mathrm{O}(\mathrm{III})^{2-} \text {. }}$
When a vacancy is introduced in oxide materials, it is sometimes observed that extra electronic levels appear in the band gap. This is also the case for $\mathrm{V}_{\mathrm{H}^{+}}$and $\mathrm{V}_{\mathrm{OH}^{-}}$in $\mathrm{HAp}$, in which the extra levels just above the VBM and below the conduction band minimum $(\mathrm{CBM})$ are present, respectively (denoted by the arrows in the figure). As can be seen from the wave-function plots in Figs. 5(a) and 5(b), these levels are both localized around the vacancy sites. The extra level of $\mathrm{V}_{\mathrm{H}^{+}}$is composed of the $\mathrm{O}$ (IV) $2 p$ orbitals at the first nearest-neighbor (1st NN) site, originating from the upper $\mathrm{VB}$, while the one for $\mathrm{V}_{\mathrm{OH}^{-}}$is a mixture of the neighboring $\mathrm{H} 1 s$ and $\mathrm{Ca} 3 d 4 s$ components, arising from the CB. They can be considered, therefore, as the acceptorlike and donorlike levels induced by the vacancy formation.

As compared to the above two vacancies, $\mathrm{V}_{\mathrm{Ca}(\mathrm{I})^{2+} \text {, }}$ $\mathrm{V}_{\mathrm{O}(\mathrm{III})^{2-}}$, and $\mathrm{V}_{\mathrm{O}(\mathrm{IV})^{2-}}$ do not exhibit a deep extra level within the band gap. For example, however, the highest electronoccupied level for $\mathrm{V}_{\mathrm{Ca}(\mathrm{I})^{2+}}$ is located slightly above the VBM, which indicates the presence of the shallow acceptorlike level at the VB edge. This result is also confirmed by the wave function shown in Fig. 5(c), which consists of $\mathrm{O} 2 p$ components at the 1st NN sites from the vacancy.

It should be noted that the $\mathrm{V}_{\mathrm{O}(\mathrm{III})^{2-}}$ defect shows the extra levels around $-9.5 \mathrm{eV}$ and $-21.3 \mathrm{eV}$. As an example, the contour map of the wave function at $-9.5 \mathrm{eV}$ is displayed in Fig. 5(d). The extra level is not localized around the vacancy site, and the main component is the $\mathrm{O}$ (II) $2 p$ orbitals forming the adjacent $\mathrm{PO}_{4}$ tetrahedron. In order to show the relaxed atomic structure around $\mathrm{V}_{\mathrm{O}(\mathrm{III})^{2-}}$ more clearly, the ED contour map on the $\{1 \overline{1} 00\}$ plane for the $\mathrm{V}_{\mathrm{O}(\mathrm{III})^{2-}}$ supercell is plotted in Fig. 6, together with the one for the perfect lattice. As stated in Sec. III A, the HAp crystal contains $\mathrm{PO}_{4}$ tetrahedra and $\mathrm{OH}$ groups with $\mathrm{Ca}$ atoms in between. In the 
(a) $\mathrm{V}_{\mathrm{H}^{+}}$

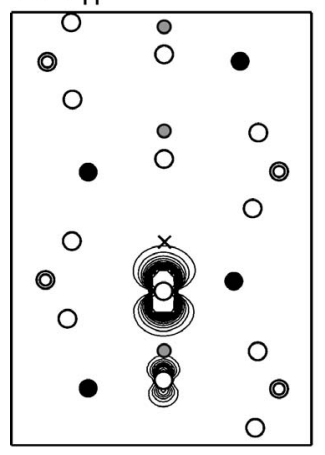

(b)

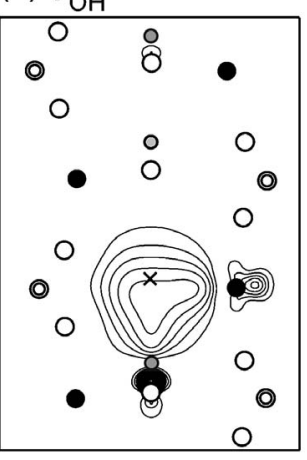

(c) $\mathrm{V}_{\mathrm{Ca}(1)^{2+}}$

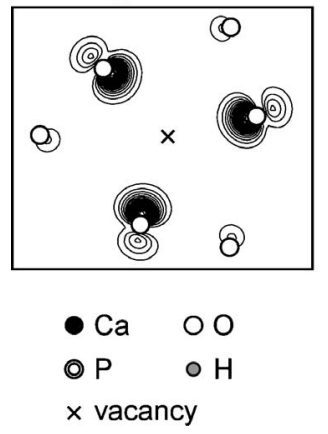

(d) $\mathrm{V}_{\mathrm{O}(I I I)^{2-}}$

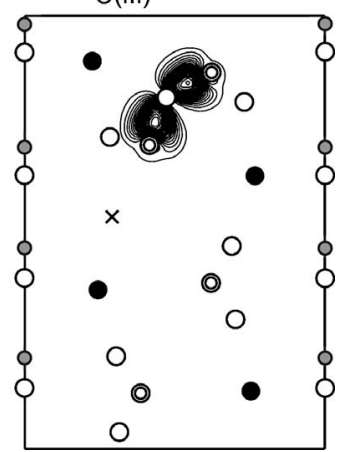

FIG. 5. Contour maps of the wave functions induced by the vacancies (denoted by the arrows in Fig. 4). (a), (b), and (d) are cross sections on the $\{1 \overline{1} 00\}$ plane, while (c) on the $\{0001\}$ plane.

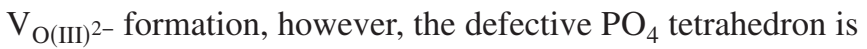
significantly distorted, and the $\mathrm{P}$ atom missing the bond with $\mathrm{O}(\mathrm{III})\left[\mathrm{P}^{*}\right.$ in Fig. 6(b) $]$ tends to have bonding with the $\mathrm{O}$ (II) atom that belongs to the adjacent $\mathrm{PO}_{4}$ tetrahedron. This indicates that the dangling bond state of the $\mathrm{P}^{*}$ atom by the
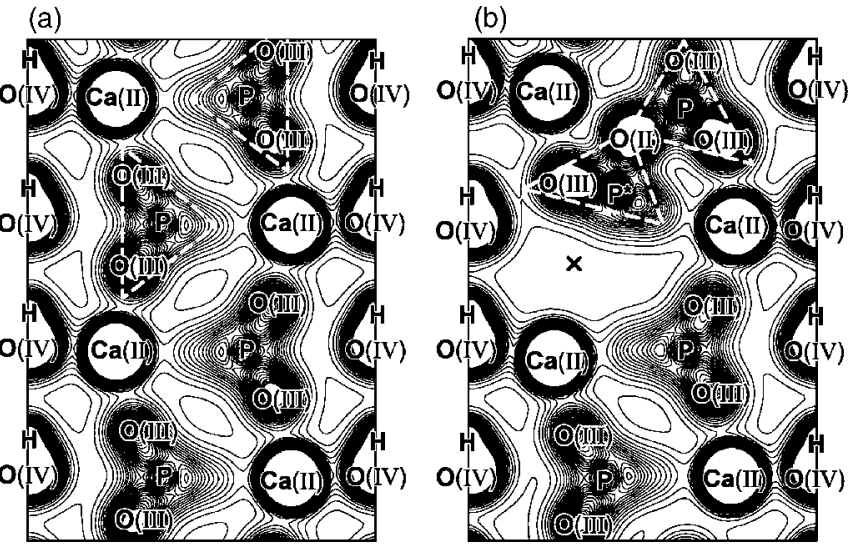

FIG. 6. Electron density maps on the $\{1 \overline{1} 00\}$ plane for (a) the perfect supercell and (b) the supercell with $V_{\mathrm{O}(\mathrm{III})^{2-}}$. The $\mathrm{P}^{*}$ atom in (b) was originally the $1 \mathrm{st} \mathrm{NN}$ atom to the $\mathrm{O}$ (III) that is removed to form the vacancy. The triangles drawn by the broken lines display the locations of the $\mathrm{PO}_{4}$ tetrahedra.

$\mathrm{V}_{\mathrm{O}(\mathrm{III})^{2-}}$ formation is energetically unstable. In fact, as shown in Fig. 2, the energy levels arising from P-O bonds are located around the lower part of the VB (peaks A and B), which are far below the VBM. When $\mathrm{V}_{\mathrm{O}(\mathrm{III})^{2-}}$ is formed, therefore, $\mathrm{O}-2 p$ electrons in the upper VB tend to occupy the dangling bond state of $\mathrm{P}^{*}$, in order to stabilize the electronic energy of the system. In this case, this is realized by the bonding formation of $\mathrm{P}^{*}$ with $\mathrm{O}$ (II) in the adjacent $\mathrm{PO}_{4}$ tetrahedron, accompanying the substantial structural relaxation.

In order to investigate structural characteristics around vacancies, the distances from vacancy sites to neighboring atoms are summarized in Table II. Due to the low symmetry of the HAp structure, particular atoms in a certain coordination shell from a vacancy site are not always located at the same

TABLE II. Average distances (in $\mathrm{nm}$ ) from the vacancies to their neighboring atoms. The distances before relaxation are shown in parentheses, in which the asterisk indicates that the atoms with that length are the first neighboring ones from the vacancy sites.

\begin{tabular}{|c|c|c|c|c|}
\hline Vacancy & 1 st NN & 2nd NN & 3rd NN & 4th NN \\
\hline $\mathrm{V}_{\mathrm{Ca}(\mathrm{I})^{2+}}$ & $\begin{array}{c}3 \mathrm{O}(\mathrm{I})=0.266\left(0.244^{*}\right) \\
3 \mathrm{O}(\mathrm{II})=0.265\left(0.248^{*}\right)\end{array}$ & $3 \mathrm{O}(\mathrm{III})=0.295(0.280)$ & $\begin{array}{c}2 \mathrm{Ca}(\mathrm{I})=0.329(0.345) \\
3 \mathrm{P}=0.331(0.323)\end{array}$ & $3 \mathrm{P}=0.371(0.364)$ \\
\hline $\mathrm{V}_{\mathrm{Ca}(\mathrm{II})^{2+}}$ & $\mathrm{H}=0.153(0.269)$ & $\begin{array}{c}\mathrm{O}(\mathrm{II})=0.241\left(0.237^{*}\right) \\
2 \mathrm{O}(\mathrm{III})=0.249\left(0.236^{*}\right) \\
\mathrm{O}(\mathrm{IV})=0.250\left(0.240^{*}\right)\end{array}$ & $\mathrm{O}(\mathrm{III})=0.259\left(0.252^{*}\right)$ & $\mathrm{O}(\mathrm{III})=0.275\left(0.248^{*}\right)$ \\
\hline $\mathrm{V}_{\mathrm{H}^{+}}$ & $\mathrm{O}(\mathrm{IV})=0.156(0.098 *)$ & $3 \mathrm{Ca}(\mathrm{II})=0.253(0.269)$ & $\mathrm{O}(\mathrm{IV})=0.262(0.247)$ & $3 \mathrm{O}(\mathrm{III})=0.295(0.298)$ \\
\hline $\mathrm{V}_{\mathrm{O}(\mathrm{I})^{2-}}$ & $\mathrm{P}=0.253\left(0.155^{*}\right)$ & $\begin{array}{c}2 \mathrm{Ca}(\mathrm{I})=0.265(0.242 *) \\
\mathrm{O}(\mathrm{II})=0.263(0.257) \\
2 \mathrm{O}(\mathrm{III})=0.269(0.257)\end{array}$ & $\mathrm{O}(\mathrm{I})=0.274(0.296)$ & $\begin{array}{l}\mathrm{Ca}(\mathrm{II})=0.294(0.281) \\
2 \mathrm{O}(\mathrm{II})=0.292(0.300)\end{array}$ \\
\hline $\mathrm{V}_{\mathrm{O}(\mathrm{II})^{2-}}$ & $\mathrm{O}(\mathrm{III})=0.200(0.251)$ & $\begin{array}{c}\mathrm{P}=0.216\left(0.156^{*}\right) \\
\mathrm{O}(\mathrm{III})=0.228(0.253)\end{array}$ & $\mathrm{Ca}(\mathrm{I})=0.248\left(0.248^{*}\right)$ & $\begin{aligned} \mathrm{Ca}(\mathrm{II}) & =0.259\left(0.237^{*}\right) \\
\mathrm{O}(\mathrm{II}) & =0.256(0.302)\end{aligned}$ \\
\hline $\mathrm{V}_{\mathrm{O}(\mathrm{III})^{2-}}$ & $\mathrm{O}(\mathrm{III})=0.243(0.251)$ & $\begin{array}{c}2 \mathrm{Ca}(\mathrm{II})=0.258\left(0.242^{*}\right) \\
\mathrm{P}=0.252\left(0.156^{*}\right)\end{array}$ & $\begin{array}{l}\mathrm{O}(\mathrm{I})=0.271(0.256) \\
\mathrm{O}(\mathrm{II})=0.268(0.253)\end{array}$ & $\begin{array}{c}\mathrm{O}(\mathrm{I})=0.289(0.302) \\
\mathrm{O}(\mathrm{II})=0.290(0.299) \\
2 \mathrm{O}(\mathrm{III})=0.297(0.310)\end{array}$ \\
\hline $\mathrm{V}_{\mathrm{O}(\mathrm{IV})^{2-}}$ & $\mathrm{H}=0.042\left(0.098^{*}\right)$ & $\begin{array}{c}3 \mathrm{Ca}(\mathrm{II})=0.249\left(0.240^{*}\right) \\
\mathrm{H}=0.244(0.247)\end{array}$ & $3 \mathrm{O}(\mathrm{III})=0.305(0.316)$ & $3 \mathrm{O}(\mathrm{III})=0.323(0.326)$ \\
\hline $\mathrm{V}_{\mathrm{OH}^{-}}$ & $\mathrm{H}=0.254(0.247)$ & $3 \mathrm{Ca}(\mathrm{II})=0.269\left(0.240^{*}\right)$ & $3 \mathrm{O}(\mathrm{III})=0.294(0.316)$ & $3 \mathrm{O}(\mathrm{III})=0.308(0.326)$ \\
\hline
\end{tabular}


TABLE III. P*-O bond lengths in the tetrahedra formed by the oxygen vacancies. The $\mathrm{P}^{*}$ atom is originally the 1 st $\mathrm{NN}$ atom to the vacancy sites but is significantly displaced due to the vacancy formation [see Fig. 6(b) for the $\mathrm{V}_{\mathrm{O}(\mathrm{III})^{2-}}$ case].

\begin{tabular}{lc}
\hline \hline Vacancy & $\mathrm{P}^{*}$-O length (in nm) \\
\hline $\mathrm{V}_{\mathrm{O}(\mathrm{I})^{2-}}$ & $0.150,0.151,0.153,0.178$ \\
$\mathrm{~V}_{\mathrm{O}(\mathrm{II})^{2-}}$ & $0.152,0.153,0.153,0.170$ \\
$\mathrm{~V}_{\mathrm{O}(\mathrm{III})^{2-}}$ & $0.152,0.153,0.153,0.170$ \\
\hline \hline
\end{tabular}

distance. In such a case, the average distances are shown in this table.

As a general trend, cations and anions surrounding a vacancy with a positive effective charge $\left(\mathrm{V}_{\mathrm{O}^{2-}}\right.$ and $\left.\mathrm{V}_{\mathrm{OH}^{-}}\right)$show outward and inward relaxations, respectively. This can be understood by the electrostatic interactions between the charged vacancy and the surrounding ions. This trend is reversed for the vacancies with a negative effective charge $\left(\mathrm{V}_{\mathrm{Ca}(\mathrm{I})^{2+}}\right.$ and $\left.\mathrm{V}_{\mathrm{H}^{+}}\right)$. It is noted that in the $\mathrm{V}_{\mathrm{O}(\mathrm{IV})^{2-}}$ case, the distance to the 1st NN $\mathrm{H}$ from the vacancy site becomes smaller than that in the perfect lattice, although the $\mathrm{H}^{+}$and $\mathrm{V}_{\mathrm{O}(\mathrm{IV})^{2-}}$ both have positive charges. This is attributed to the large ionic size of $\mathrm{O}(\mathrm{IV})^{2-}$. In the $\mathrm{O}(\mathrm{IV})^{2-}$ vacancy formation, the open space due to the missing $\mathrm{O}^{2-}$ is produced, and thus the 1 st $\mathrm{NN} \mathrm{H}^{+}$can undergo slight inward relaxation.

As stated for $\mathrm{V}_{\mathrm{O}(\mathrm{III})^{2-}}$ in Figs. 5 and 6, significant relaxations around $\mathrm{V}_{\mathrm{O}(\mathrm{I})^{2-}}, \mathrm{V}_{\mathrm{O}(\mathrm{II})^{2-}}$, and $\mathrm{V}_{\mathrm{O}(\mathrm{III})^{2-}}$ take place. This can be seen from changes in distance from the vacancy sites to the nearest neighboring $\mathrm{P}$ atoms. The $\mathrm{P}$ atom moves away from the vacancy sites by more than $38 \%$. In the cases of

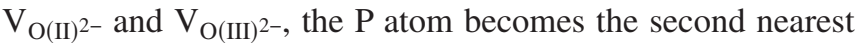
neighbor (2nd NN) atom after relaxation, while the $\mathrm{O}(\mathrm{III})$ atom is located at the 1st NN site. As a result, the displaced $\mathrm{P}$ atom, corresponding to $\mathrm{P}^{*}$ in Fig. 6(b) for $\mathrm{V}_{\mathrm{O}(\mathrm{III})^{2-}}$, forms a different $\mathrm{PO}_{4}$ tetrahedron in which one oxygen atom is shared with the adjacent $\mathrm{PO}_{4}$ tetrahedron. The resulting $\mathrm{P}^{*}$-O bond lengths for the $\mathrm{V}_{\mathrm{O}(\mathrm{III})^{2-}}$ case are listed in Table III. As compared to the original P-O length of $0.156 \mathrm{~nm}$, one of the $\mathrm{P}^{*}-\mathrm{O}$ lengths in the tetrahedra is considerably elongated (more than $8 \%$ ). It can be said, therefore, that the $\mathrm{P}^{*} \mathrm{O}_{4}$ tetrahedra undergo substantial distortion, which may be related to the vacancy stability.

\section{Vacancy formation energies}

Based on the supercell calculations for the vacancies in HAp, formation energies of possible vacancies in HAp are evaluated, and dominant vacancy species and their energetics are investigated.

Figure 7(a) shows the calculated formation energies per defect for vacancies in HAp as a function of temperature. In this figure, $p_{\mathrm{H}_{2} \mathrm{O}}$ of $0.67 \mathrm{kPa}$ (=5 Torr) is used to evaluate the formation energies (see Sec. II), because the similar $p_{\mathrm{H}_{2} \mathrm{O}}$ condition was sometimes employed in the previous experiments. ${ }^{1,7}$ For charged vacancies, possible defect reactions are considered so as to maintain charge neutrality of the
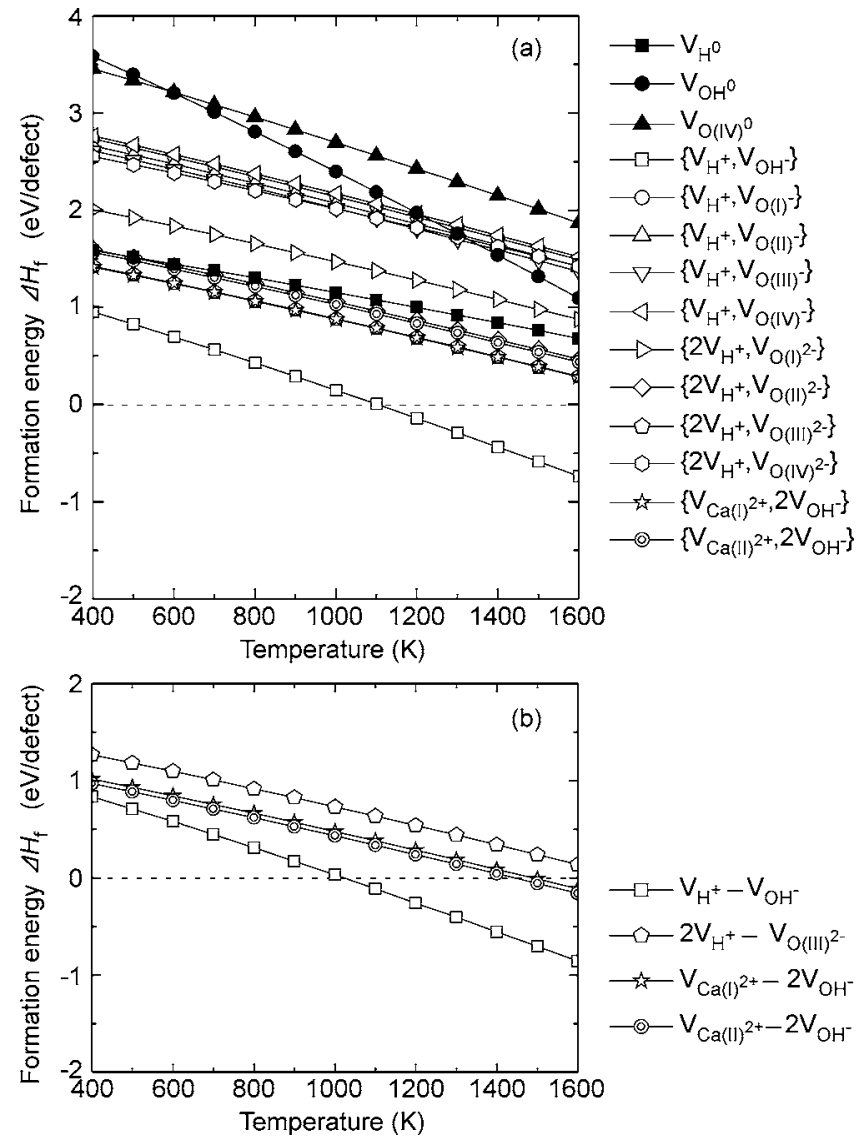

FIG. 7. Calculated vacancy formation energies in HAp as a function of temperature at $p_{\mathrm{H}_{2} \mathrm{O}}=0.67 \mathrm{kPa}$. In this figure, only vacancies having formation energies of less than $2.0 \mathrm{eV}$ in this temperature range are shown. (a) The vacancy reactions without association between the charged vacancy species and (b) the vacancy complexes.

system, and their formation energies per defect in Fig. 7(a) are obtained by summing the formation energies of the individual charged vacancies. It is noted, therefore, that interactions between charged vacancies are not taken into account in Fig. 7(a). In fact, more than 30 kinds of vacancy reactions including formation of isolated neutral vacancies are investigated, and only those having formation energies of less than $2.0 \mathrm{eV}$ per defect in this temperature range are plotted here.

It is obvious that an $\mathrm{OH}^{-}$vacancy with a $\mathrm{H}^{+}$vacancy $\left(\left\{\mathrm{V}_{\mathrm{H}^{+}}, \mathrm{V}_{\mathrm{OH}^{-}}\right\}\right)$exhibits the smallest formation energy in the entire temperature range. The formation energy of $\left\{\mathrm{V}_{\mathrm{H}^{+}}, \mathrm{V}_{\mathrm{OH}^{-}}\right\}$becomes negative at temperatures above $1100 \mathrm{~K}$, which indicates that spontaneous formation of the vacancy pair is possible at the high temperatures. In contrast, the $\mathrm{V}_{\mathrm{O}^{-}}$or $\mathrm{V}_{\mathrm{O}^{2-}}$ defects are more difficult to be formed for charge compensation of $\mathrm{V}_{\mathrm{H}^{+}}$. This can be understood from the chemical bonding environments of the oxygen atoms in HAp. As can be seen in Figs. 2 and 3, the O(I), O(II), and $\mathrm{O}$ (III) atoms have covalent interactions with $\mathrm{P}$, while the $\mathrm{O}(\mathrm{IV})$ atom is covalently bonded to the neighboring $\mathrm{H}$ atom by admixture between $\mathrm{O} 2 s p$ and $\mathrm{H} 1 s$ orbitals. In order to introduce the oxygen vacancies, such a strong $\mathrm{P}-\mathrm{O}$ or $\mathrm{H}-\mathrm{O}$ 
TABLE IV. Association energies for the vacancy complexes in HAp. The negative values indicate attractive interactions between the individual vacancy species.

\begin{tabular}{lc}
\hline \hline Vacancy complex & $\begin{array}{c}\text { Association energy } \\
(\mathrm{eV} / \text { defect })\end{array}$ \\
\hline $\mathrm{V}_{\mathrm{H}^{+}}-\mathrm{V}_{\mathrm{OH}^{-}}$ & -0.12 \\
$2 \mathrm{~V}_{\mathrm{H}^{+}}-\mathrm{V}_{\mathrm{O}(\mathrm{III})^{2-}}$ & -0.16 \\
$\mathrm{~V}_{\mathrm{Ca}(\mathrm{I})^{2+}-2} \mathrm{~V}_{\mathrm{OH}^{-}}$ & -0.40 \\
$\mathrm{~V}_{\mathrm{Ca}(\mathrm{II})^{2+}}-2 \mathrm{~V}_{\mathrm{OH}^{-}}$ & -0.60 \\
\hline \hline
\end{tabular}

bond should be broken, which may result in the larger formation energies of $\mathrm{V}_{\mathrm{O}^{-}}$or $\mathrm{V}_{\mathrm{O}^{2-}}$. For example, the large formation energy of $\mathrm{O}(\mathrm{III})^{2-}$ vacancy can also be imagined from the substantial displacement of the adjacent $\mathrm{P}$ atom so as to make the distorted $\mathrm{PO}_{4}$ tetrahedron, as shown in Fig. 6(b). When the pair of $\mathrm{O}(\mathrm{IV})^{2-}$ and $\mathrm{H}^{+}$at the same $\mathrm{OH}$ site is simultaneously removed as an $\mathrm{OH}^{-}$group, however, the strong internal $\mathrm{H}-\mathrm{O}$ bond is apparently prevented from breaking, and it is thus thought that the $\mathrm{OH}^{-}$vacancy with $\mathrm{V}_{\mathrm{H}^{+}}\left(\left\{\mathrm{V}_{\mathrm{H}^{+}}, \mathrm{V}_{\mathrm{OH}^{-}}\right\}\right)$can be stably formed in HAp.

On the other hand, $\mathrm{V}_{\mathrm{Ca}^{2+}}$ as a charge-compensating vacancy for $\mathrm{V}_{\mathrm{OH}^{-}}\left(\left\{\mathrm{V}_{\mathrm{Ca}^{2+}}, 2 \mathrm{~V}_{\mathrm{OH}^{-}}\right\}\right)$exhibits a larger formation energy than $\mathrm{V}_{\mathrm{H}^{+}}\left(\left\{\mathrm{V}_{\mathrm{H}^{+}}, \mathrm{V}_{\mathrm{OH}^{-}}\right\}\right)$. This may be mainly due to a difference in atomic coordination between $\mathrm{Ca}^{2+}$ and $\mathrm{H}^{+}$. As stated before, $\mathrm{H}^{+}$is only coordinated to one $\mathrm{O}(\mathrm{IV})$ atom, whereas $\mathrm{Ca}^{2+}$ is surrounded by six oxygen ions (see also Table II). Although the bonding characters of individual $\mathrm{H}-\mathrm{O}$ and $\mathrm{Ca}-\mathrm{O}$ pairs are different from each other, the removal of $\mathrm{Ca}^{2+}$, having the larger coordination number with oxygen, is energetically unfavorable as compared to the $\mathrm{V}_{\mathrm{H}^{+}}$formation.

When the vacancy species have effective charges, they may interact with one another in an electrostatic manner. There is a possibility that such interactions between charged vacancies will affect the results in Fig. 7(a), namely, the relative stability of the possible vacancy reactions. In order to address the issue, vacancy complexes of $\mathrm{V}_{\mathrm{H}^{+}}-\mathrm{V}_{\mathrm{OH}^{-}}, 2 \mathrm{~V}_{\mathrm{H}^{+}}$

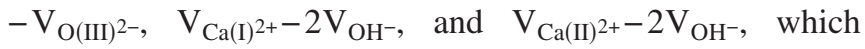
show the relatively small formation energies in Fig. 7(a), are selected. For each complex, the vacancy species in the possible nearest neighboring configuration are put in the same 88 -atom supercell. Association energies in the vacancy complexes are calculated by the formation energies of the vacancy complexes minus those of the isolated vacancy species. When the association energies are negative, the vacancy species can be present as the complexes in HAp. The calculated association energies are summarized in Table IV and the formation energies of the complexes as a function of temperature are plotted in Fig. 7(b). It is found that the association energies for the complexes are negative and, in particular, the $\mathrm{V}_{\mathrm{Ca}(\mathrm{II})^{2+}}-2 \mathrm{~V}_{\mathrm{OH}^{-}}$complex exhibits the strongest association. However, the formation energy of the $\mathrm{V}_{\mathrm{H}^{+}}$ $-\mathrm{V}_{\mathrm{OH}^{-}}$complex is still the smallest and becomes negative above $1000 \mathrm{~K}$. It can be concluded, therefore, that the formation of the $\mathrm{V}_{\mathrm{H}^{+}}$and $\mathrm{V}_{\mathrm{OH}^{-}}$pair is energetically most favorable at high temperatures.
There were a number of experiments on the thermal stability of HAp under different atmospheres, such as in vacuum or in air with water vapor of a low partial pressure. ${ }^{1,6,7}$ It seems likely that the evolution of water from HAp takes place at high temperatures, where the following reaction with respect to formation of $\mathrm{OH}^{-}$vacancies was postulated:

$$
\begin{aligned}
\mathrm{Ca}_{10}\left(\mathrm{PO}_{4}\right)_{6}(\mathrm{OH})_{2}= & \mathrm{Ca}_{10}\left(\mathrm{PO}_{4}\right)_{6}(\mathrm{OH})_{2-2 x} \mathrm{O}_{x}\left(\mathrm{~V}_{\mathrm{OH}}\right)_{x} \\
& +x \mathrm{H}_{2} \mathrm{O}(\text { gas }) .
\end{aligned}
$$

This implies that when an $\mathrm{OH}^{-}$vacancy is produced in HAp, $\mathrm{a} \mathrm{H}^{+}$is also removed for charge compensation. In this regard, our calculations also show that the vacancy pair of $\left\{\mathrm{V}_{\mathrm{H}^{+}}, \mathrm{V}_{\mathrm{OH}^{-}}\right\}$is dominantly formed in HAp by thermal treatments, which is consistent with the vacancy formation mechanism described in Eq. (8).

It should be noted that the calculated formation energy of $\left\{\mathrm{V}_{\mathrm{H}^{+}}, \mathrm{V}_{\mathrm{OH}^{-}}\right\}$becomes zero at around $1000 \mathrm{~K}$. Accordingly, the $\left\{\mathrm{V}_{\mathrm{H}^{+}}, \mathrm{V}_{\mathrm{OH}^{-}}\right\}$pair can be formed spontaneously above that temperature, which indicates that HAp is easily dehydrated, leading to stable nonstoichiometry with respect to the $\mathrm{OH}$ group. In fact, previous experiments suggested that HAp starts to lose water, producing a remarkable amount of $\mathrm{OH}$ defects [see Eq. (8)], at temperatures as low as $1073 \mathrm{~K} .{ }^{1,6,7}$ Stoichiometric HAp itself may no longer be stable above $1073 \mathrm{~K}$ and results in a highly defective structure containing $\left\{\mathrm{V}_{\mathrm{H}^{+}}, \mathrm{V}_{\mathrm{OH}^{-}}\right\}$, which corresponds to the formation of a solid solution of HAp and oxyapatite $\left[\mathrm{Ca}_{5}\left(\mathrm{PO}_{4}\right)_{3} \mathrm{O}_{0.5}\right.$, fully dehydrated HAp]. ${ }^{1}$ It can be said, therefore, that the temperature dependence of $\Delta H_{\mathrm{f}}\left(\left\{\mathrm{V}_{\mathrm{H}^{+}}, \mathrm{V}_{\mathrm{OH}^{-}}\right\}\right)$in Fig. 7 is closely related to the observed thermal stability of HAp.

In this study, electronic structures and stable vacancy defects in HAp were investigated by first-principles calculations. In $\mathrm{HAp}, \mathrm{PO}_{4}$ tetrahedra are formed by firmly bonded $\mathrm{P}-\mathrm{O}$ pairs, and $\mathrm{Ca}$ ions play a role for connecting the $\mathrm{PO}_{4}$ tetrahedra and $\mathrm{OH}$ groups via ionic $\mathrm{Ca}-\mathrm{O}$ bonds. Regarding vacancy formation in HAp, it was found that vacancies of $\mathrm{OH}^{-}$and $\mathrm{H}^{+}$can be easily formed. The vacancy-formation mechanism and its temperature-dependent energetics can reasonably explain previous experimental results. Since it can be considered that point defects in HAp are important for physical and chemical properties of the HAp materials, firstprinciples analyses are expected to be useful for further understanding and development of HAp-based materials.

\section{SUMMARY}

First-principles plane-wave base calculations were performed for HAp and the characteristic electronic structures and vacancy formation energies were investigated. The results obtained can be summarized as follows:

(1) In the upper and lower VBs of HAp, P-3sp and O $-2 s p$ orbitals are admixed well with each other, which indicates strong covalent bond formation of $\mathrm{P}-\mathrm{O}$. In contrast, $\mathrm{Ca}$ atoms have ionic interactions with the adjacent $\mathrm{O}$ atoms, and 
ionic Ca-O bonds play a role for connecting the $\mathrm{PO}_{4}$ tetrahedra and $\mathrm{OH}$ groups.

(2) Among possible point-defect reactions, an $\mathrm{OH}^{-}$vacancy accompanying a $\mathrm{H}^{+}$vacancy $\left(\left\{\mathrm{V}_{\mathrm{H}^{+}}, \mathrm{V}_{\mathrm{OH}^{-}}\right\}\right)$exhibits the smallest formation energy. The vacancies related to the $\mathrm{OH}$ columns can be dominantly present in HAp.

(3) It was also found that the formation energy for $\left\{\mathrm{V}_{\mathrm{H}^{+}}, \mathrm{V}_{\mathrm{OH}^{-}}\right\}$becomes negative at temperatures higher than around $1000 \mathrm{~K}$, which indicates that their spontaneous formation is possible. This corresponds to the observed non- stoichiometry of HAp due to $\mathrm{OH}$ deficiency, experimentally observed at around $1073 \mathrm{~K}$.

\section{ACKNOWLEDGMENTS}

This work was supported by a Grant-in-Aid for Scientific Research from the Ministry of Education, Sports, Science, and Culture of Japan. The authors also acknowledge Isao Tanaka at Kyoto University for useful discussion.
${ }^{1}$ J. C. Elliot, Structure and Chemistry of the Apatites and Other Calcium Orthophosphates (Elsevier Science, Amsterdam, 1994).

${ }^{2}$ J. C. Elliot, Science 180, 1055 (1973).

${ }^{3}$ K. Sudarsanan and R. A. Young, Acta Crystallogr., Sect. B: Struct. Crystallogr. Cryst. Chem. 25, 1534 (1969).

${ }^{4}$ J. Y. Kim, R. R. Fenton, B. A. Hunter, and B. J. Kennedy, Aust. J. Chem. 53, 679 (2000).

${ }^{5}$ P. Alberius-Henning, E. Adolfsson, and J. Grins, J. Mater. Sci. 36, 663 (2001).

${ }^{6}$ J. C. Trombe and G. Montel, J. Inorg. Nucl. Chem. 40, 15 (1978).

${ }^{7}$ H. Fujimori, H. Toya, K. Ioku, S. Goto, and M. Yoshimura, Chem. Phys. Lett. 325, 383 (2000).

${ }^{8}$ K. Yamashita, K. Kitagaki, and T. Umegaki, J. Am. Ceram. Soc. 78, 1191 (1995).

${ }^{9}$ I. Tanaka, K. Tatsumi, M. Nakano, H. Adachi, and F. Oba, J. Am. Ceram. Soc. 85, 68 (2002).

${ }^{10}$ K. Matsunaga, T. Tanaka, T. Yamamoto, and Y. Ikuhara, Phys. Rev. B 68, 085110 (2003).

${ }^{11}$ K. Matsunaga, A. Nakamura, T. Yamamoto, and Y. Ikuhara, Phys. Rev. B 68, 214102 (2003).

${ }^{12}$ L. Calderín, M. J. Stott, and A. Rubio, Phys. Rev. B 67, 134106
(2003).

${ }^{13}$ P. Rulis, L. Ouyang, and W. Y. Ching, Phys. Rev. B 70, 155104 (2004).

${ }^{14}$ R. Astala, L. Calderín, X. Yin, and M. J. Stott, Chem. Mater. 18, 413 (2006).

${ }^{15}$ D. U. Schramm, J. Terra, A. M. Rossi, and D. E. Ellis, Phys. Rev. B 63, 024107 (2000).

${ }^{16}$ M. I. Kay, R. A. Young, and A. S. Posner, Nature (London) 204, 1050 (1964).

${ }^{17}$ G. Kresse and J. Furthmüller, Phys. Rev. B 54, 11169 (1996).

${ }^{18}$ G. Kresse and J. Furthmüller, Comput. Mater. Sci. 6, 15 (1996).

${ }^{19}$ P. E. Blöchl, Phys. Rev. B 50, 17953 (1994).

${ }^{20}$ G. Kresse and D. Joubert, Phys. Rev. B 59, 1758 (1999).

${ }^{21}$ J. P. Perdew, K. Burke, and M. Ernzerhof, Phys. Rev. Lett. 77, 3865 (1996).

${ }^{22}$ H. J. Monkhorst and J. D. Pack, Phys. Rev. B 13, 5188 (1976).

${ }^{23}$ M. W. Chase, Jr., NIST-JANAF Thermochemical Tables, 4th ed. (The American Institute of Standards and Technology, New York, 1998).

${ }^{24}$ L. Calderín, D. Dunfield, and M. J. Stott, Phys. Rev. B 72, 224304 (2005). 